\title{
A Clinical Study of Ectopic Pregnancies in a Tertiary Care Hospital of Chittagong, Bangladesh
}

\author{
Most. Sabina Yeasmin ${ }^{1 *}$ \\ $M$ Jalal Uddin² \\ Enamul Hasan ${ }^{1}$ \\ 'Department of Obstetrics and Gynecology \\ Chattagram Maa-O-Shishu Hospital Medical College \\ Chittagong,Bangladesh. \\ ${ }^{2}$ Department of Community Medicine \\ Chattagram Maa-O-Shishu Hospital Medical College \\ Chittagong,Bangladesh.
}

\begin{abstract}
Background: Motherhood, an eternal, universal and inherent dream which every woman has. This dream may not always be pleasant and it can involve nightmares. One of this is ectopic pregnancy: A pregnancy which can be life threatening. Aims : 1. To know the age group, parity, gestational age and the risk factors with respect to the ectopic pregnancy. 2. To know the clinical presentation of the ectopic pregnancy. 3. To know the treatment and morbidity and mortality associated with ectopic pregnancy. Materials \& methods : A total of 47 admitted patients who were diagnosed as ectopic pregnancy cases were retrospective analyzed between the periods from January 2013 to June 2014 at Chattagram Maa-O-Shishu Hospital Medical College, Agrabad, Chittagong. The following parameters: age, parity, gestational age, risk factors, clinical presentation, need for blood transfusion and findings on ultrasonogram and at surgery and morbidity associated with ectopic pregnancy were noted Results: The incidence of the ectopic pregnancy in the present study was 7.4/1000 deliveries. A majority of the cases were multigravidas and majority of the cases gestational age were six to ten weeks. In most of the cases, there were no identifiable risk factors. The commonest risk factors present were history of MR (12.7\%)and abortion (10.6), history of tubal surgery (2.2\%), infertility (2.2\%) and pelvic inflammatory diseases $(4.2 \%)$. The commonest symptoms were abdominal pain $(89.3 \%)$, amenorrhea $(78.7 \%)$ and abnormal vaginal bleeding $(63.5 \%)$; and commonest signs were abdominal tenderness $(70.5 \%)$, cervical excitation (52.6\%) and adnexal tenderness (50.4\%). Almost half (45\%) were in a state of shock at admission. Ultrasound, a urine pregnancy test and serum B-hCG were the investigative modalities which were used. Surgery by open method in the form of salpingectomy (92.3\%), salpingo-oophorectomy (5.5\%) and salpingostomy $(2.1 \%)$ were the mainstay of management. Morbidity included anemia $(50.9 \%)$, blood transfusion $(78 \%)$ and wound infection $(2.1 \%)$. No maternal mortality noted. Conclusion: Early diagnosis, identifying of underlying risk factors and timely intervention in the form of conservative or surgical treatment will help in reducing the morbidity and mortality associated with ectopic pregnancy.
\end{abstract}

Key words: Amenorrhea; Hemoperitoneum; Ruptured ectopic; Salpingectomy; Vaginal bleeding.

\section{INTRODUCTION}

An ectopic pregnancy is one in which the fertilized ovum becomes implanted in a site other than the normal uterine cavity ${ }^{1}$. It is the most important cause of maternal mortality and morbidity in the first trimester ${ }^{2}$.
Department of Obstetrics and Gynecology

Chittagong, Bangladesh.

Mobile: +8801914339095

E-mail: drsabinah@yahoo.com

w w w. c mosh m cj. org 
In developing countries, a majority of hospital-based studies have reported ectopic pregnancy case-fatality rates of around $1 \%-3 \%, 10$ times higher than those reported in developed countries ${ }^{3}$.

Although women with ectopic pregnancy frequently have no identifiable risk factors, a prospective case-controlled study has shown that increased awareness of ectopic pregnancy and a knowledge of the associated risk factors helps identify women at higher risk in order to facilitate early and more accurate diagnosis ${ }^{4}$. Most risk factors are associated with risks of prior damage to the Fallopian tube. These factors include any previous pelvic or abdominal surgery, and pelvic infection ${ }^{4}$. Chlamydia trachomatis has been linked to $30-50 \%$ of all ectopic pregnancies 5 . Patients with an ectopic pregnancy commonly present with pain and vaginal bleeding between 6 and 10 weeks of gestation ${ }^{6}$. The diagnosis of ectopic pregnancy has become more frequent during the last decades but the incidence of ectopic pregnancy rupture has declined. This decline is due to quantitative hCG measurements, minimally invasive surgery and transvaginal ultrasonography ${ }^{7}$.

Early diagnosis reduces the risk of tubal rupture and allows more conservative medical treatments to be employed ${ }^{8}$.

This retrospective analysis was done to determine the incidence, clinical features, risk factors, treatment and morbidity and mortality associated with ectopic pregnancy in a tertiary care hospital.

\section{MATERIALS \& METHODS}

This was a retrospective study of ectopic pregnancies at Chattagram Maa-O-Shishu Hospital Medical College, Agrabad, Chittagong from January 2013 to June 2014. The case sheets of the patients with ectopic pregnancy were traced through the labour ward registers and operation theatre registers. Information regarding the total number of deliveries in the study period, details of demographic characteristics, clinical symptoms and signs, diagnostic tools used, treatment, risk factors for the ectopic pregnancy as well as associated morbidity and mortality were obtained. All the surgeries were partial/total salpingectomy done by open laparotomy and spinal/general anesthesia was used in all the cases.

\section{RESULTS}

During the study period of one and half year, there were a total of 6309 deliveries in our hospital and 47 cases of ectopic pregnancies were operated giving the incidence of ectopic pregnancies of 7.4/1000 deliveries.

A majority of the patients $(63.83 \%)$ belonged to the age group of 20-30 years (Table 1). $17.02 \%$ were primiparas and $82.9 \%$ were multiparas.

Risk factors were previous history of tubectomy (2.12\%), spontaneous and induced abortion (23.49\%), 2.12\% had a history of infertility. Copper-T was inserted in $4.6 \%$ cases. $11.9 \%$ had a history of D\&C. A history of previous ectopic in $(2.12 \%)$ where partial salpingectomy was done . $4.3 \%$ had a history of previous LSCS and history of PID was found in $4.2 \%$ of the case. (Table 2)
Table 1 : Age-wise distribution of total number of patients

\begin{tabular}{lcr} 
Age-group(years) & Number of patients & Percentage \\
$<20$ & 4 & $8.5 \%$ \\
$20-25$ & 21 & $44.69 \%$ \\
$26-30$ & 9 & $19.14 \%$ \\
$31-35$ & 7 & $14.90 \%$ \\
$36-40$ & 6 & $12.77 \%$ \\
Total & 47 & 100 \\
\hline
\end{tabular}

Table 2 : Risk factors for ectopic pregnancy

$\begin{array}{lcr}\text { Risk factors } & \text { Number } & \text { Percentage (\%) } \\ \text { Previous abortion and MR } & 11 & 23.4 \\ \text { Previous LSCS } & 2 & 4.3 \\ \text { Previous ectopic } & 1 & 2.1 \\ \text { Pelvic inflammatory disease } & 2 & 4.3 \\ \text { Infertility treatment } & 1 & 2.1 \\ \text { Tubal surgery (tubal ligation) } & 1 & 2.1 \\ \text { Intrauterine contraceptive device } & 2 & 4.3\end{array}$

* Some patients had multiple risk factors

The commonest presenting complaints were abdominal pain (89.3\%), amenorrhea (78.7\%) and abnormal vaginal bleeding $(63.5 \%)$. Abdominal tenderness was present in $64.5 \%$, cervical excitation in $52.6 \%$ cases and adnexal tenderness in $50.4 \%$.

The urinary pregnancy test was positive in $88.1 \%$ of the cases and Ultrasound revealed ectopic pregnancy in $80 \%$ cases.

Seasonal variation was noted in the ectopic pregnancies. A majority of the ectopic pregnancies $(59.8 \%)$ were found between January and June.

The commonest site of location of the ectopic pregnancy was in the ampulla of the fallopian tube.Other sites were fimbria, cornu, isthmus, heterotopic pregnancy and ovarian pregnancy as mentioned in (Table 3).

Table 3 : Site of ectopic pregnancies on laparotomy

$\begin{array}{lcr}\text { Site of ectopic pregnancy } & \text { Number } & \text { Percentage (\%) } \\ \text { Ampulla of fallopian tube } & 25 & 53.2 \\ \text { Cornu } & 1 & 2.1 \\ \text { Isthmus } & 10 & 21.3 \\ \text { Fimbria } & 6 & 12.7 \\ \text { Others } & & \\ \text { Heterotopic } & 2 & 4.3 \\ \text { Ovarian } & 2 & 4.3 \\ \text { Adhesions to bowel serosa } & 1 & 2.1\end{array}$

Right sided tubal pregnancy was present in 27(57.44\%) cases and left tubal involvement in $20(42.5 \%)$ cases.

Ruptured ectopic pregnancy was present in $62.3 \%$ cases on laparotomy, $24.5 \%$ had unruptured ectopic and tubal abortion in $13.9 \%$ cases. $70 \%$ of the cases showed a hemoperitoneum on laparotomy. 
The most common surgery done was unilateral salpingectomy in $44(93.6 \%)$, salpingo-oophorectomy in $2(4.3 \%)$ and salpingostomy in $1(3.2 \%)$. Morbidity included anemia $(50.9 \%)$, blood transfusion $(78.8 \%)$ and wound infection $(2.1 \%)$. No maternal mortality noted.

\section{DISCUSSION}

The prevalence of ectopic pregnancy among women who go to an emergency department with first trimester bleeding, pain, or both ranges from six to 16 percent ${ }^{9}$.

In the present study, incidence of ectopic pregnancy was 7.4/1000 deliveries. In a study conducted by Shraddha shetty K, Anil shetty 5.6/1000 delivery ${ }^{10}$. In a study conducted by RashmiGaddagi and AP Chandrashekhar, the incidence was 1: 399 pregnancies $^{11}$. In Porwal Sanjay et al study, the incidence was 2.46 per thousand of deliveries ${ }^{12}$. A majority of the patients (63.83\%) belonged to the age group of 20-30 years in the study. Similar results were found in Khaleeque et al study ${ }^{13}$. Hoover $\mathrm{KW}$ and colleagues reported that the ectopic pregnancy rate increases with age; it was $0.3 \%$ among girls and women aged $15-19$ years and $1.0 \%$ among women aged $35-44$ years $^{14} .82 .9 \%$ were multiparas and $17.02 \%$ were primiparas. Multiparous women were found to be more prone to have ectopic pregnancy $(61 \%)$ in LaxmiKarki et al study ${ }^{15}$.

The commonest predisposing factors were tubectomy, pelvic inflammatory disease, spontaneous and induced abortion, and history of infertility, prior history of Copper-T insertion, D and C, previous ectopic pregnancies and previous LSCS. Similar risk factors were noted in various other studies ${ }^{12}$. Roussos D et al in their study observed that rupture of the tube is more often observed in women with a history of ectopic pregnancy and in women with full-term pregnancy ${ }^{16}$.

The commonest presenting complaints were abdominal pain, amenorrhea and abnormal vaginal bleeding. Clinical signs included abdominal tenderness, cervical excitation and adnexal tenderness. In Porwal Sanjay et al study, 87.5\% reported with pain abdomen, bleeding per vagina encountered in $67.5 \%$ and $90 \%$ of cases had history of amenorrhea ranging from 6 weeks to 4 months. These features help in early diagnosis of ectopic pregnancies $^{12}$.

The urinary pregnancy test, Serum $\beta$-hCG and ultrasound were the diagnostic tools used for diagnosis of ectopic pregnancy. Studies have shown that Ultrasonography should be the initial investigation for symptomatic women in their first trimester; when the results are indeterminate, the serum $\beta$ human chorionic gonadotropin concentration should be measured. Serial measurement of $\beta$-hCG and progesterone concentrations may be useful when the diagnosis remains unclear ${ }^{17}$.

In the present study, seasonal variation was noted in the ectopic pregnancies. A majority of the ectopic pregnancies were found between January and june. MamdohEskandar and colleagues in a study conducted in Abha Maternity Hospital, Saudi Arabia reported that there was a seasonal variation in the incidence of ectopic pregnancy with highest mean incidence in the winter season $^{18}$. Studies have shown that as a result of the influence of season on ovarian activity, it may be plausible to anticipate a seasonal variation in the incidence of ectopic pregnancy ${ }^{19}$.
The commonest site of location of the ectopic pregnancy was in the ampulla of the fallopian tube. Ampullary part of the tube was commonly involved in most of the ectopic pregnancies in other studies ${ }^{20}$. Heterotopic pregnancy was present in $4.2 \%$ of the ectopic pregnancies. Studies have shown that in a natural conception cycles, heterotopic pregnancy is a rare event, occurring in $<1 / 30,000$ pregnancies $^{21}$. The high index of suspicion is to ensure for early and timely diagnosis and management, a timely intervention can result in a successful outcome of intrauterine pregnancy and prevent tubal rupture and hemorrhagic shock which can be fatal ${ }^{22}$.

Right sided tubal pregnancy was present in $27(57.44 \%)$ cases and left tubal involvement in 20(42.5\%) cases, consistent with other studies ${ }^{23}$. Ruptured ectopic pregnancy was present in $62.3 \%$ cases, $24.5 \%$ had unruptured ectopic and tubal abortion in $13.9 \%$ cases In Latchaw $\mathrm{G}$ et al study, tubal rupture was present in $59 \%$ cases and $41 \%$ had unruptured ectopic pregnancies. They concluded that the patients with a history of a previous ectopic pregnancy are significantly more likely to experience a tubal rupture ${ }^{24}$.

Studies have shown that low hemoglobin and hematocrit values, together with higher gravidity at the time of admission, may indicate an increased risk of tubal rupture ${ }^{25}$. In the present study, $82.9 \%$ were multiparas and $50.9 \%$ women were anemic at the time of admission.

The most common surgeries performed were partial/total salpingectomy, salpingo-oophorectomy and salpingostomy. Conservative surgery is superior to radical surgery at preserving fertility. Conservative surgery is not followed by an increased risk of repeat ectopic pregnancy, but by the risk of persistent ectopic pregnancy, which should be taken into account when deciding on the operative procedure ${ }^{26}$. Canis $\mathrm{M}$ et al in their study concluded that the surgical treatment should be performed if the patient is hemodynamically unstable, $\beta$-hCG is $>10000 \mathrm{mIU} / \mathrm{mL}$, the ectopic pregnancy is $4 \mathrm{~cm}$ in diameter, if there is a medical contraindication to methotrexate, and if the patient may not be followed adequately after treatment ${ }^{27}$

Mahboob reported a success rate of $80 \%$ by treating 12 out of 15 women with single dose MTX with initial $\beta$-hCG levels equal to $5000 \mathrm{mIU} / \mathrm{ml}^{2}$. As medical management needs extremely close follow up \& hospitalization, surgical management is still the method of choice in our country ${ }^{28}$. Laparoscopy and medical therapy have now emerged as trhe widely used therapeutic modalities with great succession terms of reduced morbidity, shoter hospital stay and conservation of fertility ${ }^{29}$. However choice depends upon early identification of ectopic pregnancy and stable condition of patients ${ }^{30}$.

Morbidity included anemia, blood transfusion and wound infection. By reducing and identifying the risk factors and 'catching' the patients at the earliest it is possible to improve the prognosis so far as morbidity, mortality and fertility are concerned $^{31}$. No maternal mortality found in our study, consistent with A. Abbas and H. Akram study ${ }^{32}$.

\section{CONCLUSION}

Early identifying of underlying risk factors, diagnosis with the essential aids like transvaginal ultrasound and -hCGand timely intervention in the form of medical or surgical treatment will definitely help in reducing the morbidity and mortality associated with ectopic pregnancy and to improve the future reproductive outcome.

\section{DISCLOSURE}

All the authors declared no competing interest. 


\section{REFERENCES}

1. Kumar p. Malhotra N. Ectopic pregnancy. Jefcoat's principles of Gynaecology. $8^{\text {th }}$ Ed;2008; 142-159.

2. Mahboob U, Mazhar SB. Management of ectopic pregnancy: a two-year study. J Ayub Med Coll Abbottabad.2006; 18(4):34-37.

3. Goyaux N, Leke R, Keita N, Thonneau P. Ectopic pregnancy in African developing countries. Acta Obstet Gynecol Scand 2003; 82:305-312.

4. Karaer A, Avsar FA, Batioglu S. Risk factors for ectopic pregnancy: a case-control study. Aust N Z J Obstet Gynaecol. 2006; 46:521-527.

5. Turner C, Horner P, et al. British Fertility Society Impact of Chlamydia trachomatis in the reproductive setting: British Fertility Society Guidelines for practice. Hum Fertil (Camb). 2010; 13:115-125.

6. Walker JJ. Ectopic pregnancy. ClinObstet Gynecol. 2007; 50: 89-99.

7. Timmerman D. Predictive models for the early diagnosis of ectopic pregnancy.Verh K Acad Geneeskd Belg. 2004; 66 (2):155-171.

8. Barnhart KT. Clinical practice. Ectopic pregnancy. N Engl J Med. 2009; 361:379-387.

9. Murray H, Baakdah H, Bardell T, Tulandi T. Diagnosis and treatment of ectopic pregnancy . CMAJ. 2005; 173(8):905.

10. Shetty S, Shetty A, A CLINICAL STUDY OF ECTOPIC PREGNANCIES. IJ MHS 2014; 4(1):305-309 http://www.innovativejournal.in/index.php/ijmhs

11. Rashmi AGaddagi, AP Chandrashekhar.A Clinical Study of Ectopic Pregnancy.JCDR 2012;6:867-869.

12. Gupta R, Porwal S, Swarnkar M, Sharma N, Maheshwari P. Incidence, trends and risk factors for Ectopic Pregnancies in a tertiary care hospital of Rajasthan. JPBMS. 2012; 16 (07):1-3.

13. Khaleeque F, Siddiqui RI, Jafarey SN. Ectopic pregnancies: A Three year study. J Pak Med Assoc. 2001; 51:240-243.

14. Hoover KW, Tao G, Kent CK. Trends in the diagnosis and treatment of ectopic pregnancy in the United States. Obstet Gynecol. 2010;115(3):495-502

15. R. C (Karki) L, Pradhan B, Duwa S. Annual Analysis of Ectopic Pregnancy in Tertiary Care Hospital. PMJN 2011;11:5-8.

16. Roussos D, Panidis D, Matalliotakis I, Mavromatidis G, Neonaki M, Mamopoulos M, Koumantakis E. Factors that may predispose to rupture of tubal ectopic pregnancy. Eur J Obstet Gynecol Reprod Biol. 2000;89(1):15-17.

17. Murray H, Baakdah H, Bardell T, TulandiT.Diagnosis and treatment of ectopic pregnancy. CMAJ. 2005;173(8):905-912.

18. Eskandar M, Archibong EI, Sadek AA, Sobande AA. Bahrain Med Bull 2002; 24 (2):63-65.

19. Warren CW, Gwinn ML, Rubin GL. Seasonal variation in conception and various pregnancy outcomes. Soc Biol 1986; 33:116-126.

20. Swende TZ. Jogo AA. Ruptured tubal pregnancy in Makurdi, North Central Nigeria. Niger J Med 2008; 17(1): 75-77.

21. Ludwig M, Kaisi M, Bauer O, Diedrich K . Heterotopic pregnancy in a spontaneous cycle: do not forget about it! Eur J Obstet Gynecol Reprod Biol. 1999; 87(1):91-93.

22. Espinosa PM, Alcantar Mendoza MA. Heterotopic pregnancy: Report of a case and review of literature. Ginecol Obstet Mex. 1997; 65:482-486.

23. GO Udigwe, OS Umeononihu, I.I Mbachu. Ectopic pregnancy: A 5 year review of cases at NnamdiAzikiwe University Teaching Hospital (NAUTH) Nnewi. NMJ 2010 ;51: 160-163

24. Latchaw G, Takacs P, Gaitan L, Geren S, Burzawa J. Risk factors associated with the rupture of tubal ectopic pregnancy. GynecolObstet Invest. 2005; 60 (3):177-180.

25. Knafel A, Basta P, Skotniczny K, Pawe M, Krzysztof B, Rokita W, Obrzut B, Wicherek . Ectopic pregnancy rupture--can it be prevented? Ginekol Pol. 2009;80(10):734-739.

26. Bangsgaard N, Lund CO, Ottesen B, Nilas L. Improved fertility following conservative surgical treatment of ectopic pregnancy. BJOG 2003; 110 (8):765-770.

27. Canis M, Savary D, Pouly JL, Wattiez A, Mage G. Ectopic pregnancy: criteria to decide between medical and conservative surgical treatment? J Gynecol Obstet Biol Reprod (Paris). 2003; 32 (7 Suppl):S54-63.

28. Chatterjee S, Dey S,Chowdhury R G,Ganguli D. Ectopic Pregnancy In Previously Infertile Women Subsequent Pregnancy Outcome After Laparoscopic Management. Al Ameen J Med Sci. 2009;2(1):67-72.

29. Jurkovie D. Ectopic pregnancy. In: Edmonds DK, editor. Dew Hurst’s textbook of Obstetrics \& Gynecology. 7 ed. USA:; Blackwell Publishers;2007.

30. Shah N, Khan NH. Ectopic pregnancy: Presentation and risk factors. J Coll Physicians Surg Pak. 2005;15:535-538.

31. Majhi AK, Roy N, Karmakar KS, Banerjee PK. Ectopic pregnancy--an analysis of 180 cases.J Indian Med Assoc. 2007;105(6):308-312.

32. Abbas A, Akram H. Ectopic Pregnancy; Audit at Maula Bakhsh Teaching Hospital Sargodha.Prof Med J 2011;18 (1): 24-27.Lozeau AM, Potter B. Diagnosis and management of ectopic pregnancy. Am Fam Physician. 2005;72:1707-1714. 